\title{
Favourable clinical outcomes following cemented arthroplasty after metal-on-metal total hip replacement: a retrospective study with a mean follow-up of 10 years
}

Weiguang $\mathrm{Yu}^{1 \dagger}{ }^{1 \dagger}$ Meiji Chen ${ }^{2 \dagger}$, Xianshang Zeng ${ }^{1}$, Mingdong Zhao ${ }^{3}$, Xinchao Zhang ${ }^{3}$, Junxing Ye ${ }^{4,5^{*}}$, Jintao Zhuang ${ }^{6 *}$ and Guowei Han ${ }^{1 *}$

\begin{abstract}
Background: Given the unexpected high rate of failure following metal-on-metal total hip replacement (MoM-THR), it is expected that more MoM-THR patients will experience revision. The long-term outcomes regarding the primary MoM-THR revised to cemented THR (CTHR) remain controversial. The purpose of this retrospective review was to evaluate the long-term outcomes of patients who underwent conversion from MoM-THR to CTHR.

Methods: A total of 220 patients (220 hips) who underwent a conversion of primary MoM-THR to CTHR from March 2006 to October 2016 were retrospectively reviewed. The primary outcomes were the functional outcomes assessed using the Harris hip scores (HHS) and major radiographic outcomes. Follow-ups occurred at 3 months, 6 months, 1 year, 2 years, and then every two years after revision.

Results: Mean follow-up was 10.1 years (5-13 years). Distinct improvements were detected in the mean HHS between the preoperative and last follow-up analysis (62.35[ \pm 8.49$]$ vs. 84.70[ $[ \pm 14.68]$, respectively, $p<0.001)$. The key orthopaedic complication rate was 18.2\% (27/148). Seven (4.7\%) cases experienced a CTHR failure at a mean of 3.4 $( \pm 1.2)$ years after revision MoM-THR, mostly attributed to recurrent dislocation.
\end{abstract}

Conclusion: CTHR might yield an acceptable functional score and a low rate of the key orthopaedic complications. Keywords: Revision, Metal-on-metal, Total hip replacement, Outcome, Cemented

\footnotetext{
*Correspondence: yejunxing0514@163.com; brianzg86@163.com; hanson9797@163.com

${ }^{+}$Weiugang Yu and Meiji Chen contributed equally to this work.

${ }^{4}$ Department of Orthopaedics, The Affiliated Hospital of Jiangnan University,

No. 1000, Hefeng Road, Binhu District, Wuxi 21400, Jiangsu, China

${ }^{6}$ Department of Urinary surgery, The First Affiliated Hospital, Sun Yat-sen

University, No. 58, Zhongshan 2nd Road, Yuexiu District, Guangzhou 510080,

China

'Department of Orthopaedics, The First Affiliated Hospital, Sun Yat-sen

University, No. 58, Zhongshan 2nd Road, Yuexiu District, Guangzhou 510080,

China

Full list of author information is available at the end of the article
}

(C) The Author(s). 2020 Open Access This article is licensed under a Creative Commons Attribution 4.0 International License, which permits use, sharing, adaptation, distribution and reproduction in any medium or format, as long as you give appropriate credit to the original author(s) and the source, provide a link to the Creative Commons licence, and indicate if changes were made. The images or other third party material in this article are included in the article's Creative Commons licence, unless indicated otherwise in a credit line to the material. If material is not included in the article's Creative Commons licence and your intended use is not permitted by statutory regulation or exceeds the permitted use, you will need to obtain permission directly from the copyright holder. To view a copy of this licence, visit http://creativecommons.org/licenses/by/4.0/ The Creative Commons Public Domain Dedication waiver (http://creativecommons.org/publicdomain/zero/1.0/) applies to the data made available in this article, unless otherwise stated in a credit line to the data. 


\section{Background}

Approximately half of patients experiencing metal-onmetal total hip replacement (MoM-THR) subsequently received leading implant-related complications with more than $1 / 3$ undertaking secondary revision surgery $[1,2]$. Implant-related complications associated with adverse reactions to metal debris (ARMD) have been an increasing concern $[3,4]$. The occurrence of these complications stimulated by ARMD which is forcefully implicated in the pathophysiology of MoM-THR failure is common and may be associated with osteolysis [5]. Furthermore, revision MoM-THR exposes to two leading challenges on the acetabular side especially when severe acetabular bone defect was reconstructed [6]. When reconstruction of acetabular bone defect related to pseudotumor was required, patients undergoing MoM-THR revised to cemented THR (CTHR) which was deemed to have the advantage of both increasing stability and persistent articulating bearing might still have secondary damage to the joints $[7,8]$. To date, there remains a discrepancy of data regarding the long-term outcomes of MoM-THR revised to CTHR $[9,10]$.

We therefore reviewed our population of patients who underwent a conversion of primary MoM-THR to CTHR to assess the 10-year follow-up outcomes. We hypothesize that submitted revision total hip surgeries without metal would provide a reasonable salvage procedure in a mid to longer-term follow-up.

\section{Methods}

\section{Study population}

Two hundred and twenty consecutive patients who were treated with CTHR after primary MoM-THR failure in the First Affiliated Hospital, Sun Yat-sen University between March 2006 and October 2016 were retrospectively reviewed. Demographic data, time to conversion, Harris hip score (HHS) prior to revision, and mechanism of injury were obtained from medical records and radiographic review. The inclusion criteria were as follows: patients who experienced conversion from initial MoMTHR (Zimmer, Warsaw, Poland) to CTHR (stem and cup, Elite, Stryker, America) with a central cup hole which can ensure that the cup is rigidly attached to the acetabular shell. The exclusion criteria included lacking research data, uncemented and hybrid THRs, congenital or acquired hip dysplasia, neuromuscular disorders, malignant tumour, severe trauma, active bleeding, poor medical conditions (i.e., acute respiratory distress syndrome, multiple organ dysfunction syndrome, diabetic acidosis, and severe malnutrition), and dementia.

The indication for MoM-THR to CTHR conversion involved ARMD, recurrent dislocation, wear, and loosening. All the conversions of MoM-THR to CTHR were performed by four fellowship-trained orthopaedist (WY,
XSZ, MZ, and XCZ) using a posterolateral approach with removal of all MoM-THR components and insertion of CTHR components. The acetabular prostheses were implanted using a press-fit technique with screws. The surgical details and postoperative management were consistent with our previous descriptions [11]. Clinical and radiological data were followed up. The patients were reviewed postoperatively at 3 months, 6 months, 12 months, 24 months by the surgeons. Subsequent reviews occurred at every two years. The primary outcomes were both the functional outcomes assessed using HHS which less than 70 was regarded as a failure and the key orthopaedic complications including implant failure, loosening, dislocation, heterotopic ossification $(\geq$ grade 3), and periprosthesis fractures. The definition of femoral and acetabular loosening was a cup migration or angular rotation exceeding $3 \mathrm{~mm}$ or a continuous radiolucent line wider than $2 \mathrm{~mm}[12,13]$. Implant failure was defined as well-defined migration and eccentric wear of the cup [14]. Heterotopic ossification was assessed using Brooker's classification [15]. Revision was defined as removal or exchange of any part of the prosthesis [16].

\section{Statistical analysis}

Comparison of functional outcomes at each follow-up was performed per Student's t-test. The date of revision for any cause was regarded as the date of implant failure. A $p$-value of less than 0.05 was used as a threshold for significance. The key statistical analyses were executed using SPSS, 26.0 (IBM Corp., Armonk, NY). Other statistical analyses were done through GraphPad Prism 8(GraphPad Software Inc., San Diego, CA, USA).

\section{Results}

In total, 220 patients who underwent MoM-THR revised to CTHR were identified. Of these, 72 (32.7\%) patients were excluded according to the current criteria, leaving 148 patients for final analysis (Fig. 1). The mean age of patients at the time of revision was 52.4 years (46-62 years). there was a male predominance ( 80 males vs. 68 females) in the cohort. The mean interval from failed MoM-THR to conversion was 6.8 years (2-9 years). The mean bone mineral density (BMD) was $-3.58(-3.1$ to 3.9). The mean HHS prior to conversion was 57.71 ( \pm 13.85). The mean follow-up was 10.1 years (5-13 years). The baseline data were presented in Table 1.

\section{Clinical outcomes}

The mean HHS after revision was presented in Table 2. Figure 2 showed the variation trend of postoperative functional scores. Noteworthy improvements were detected in the mean HHS between the preoperative and last follow-up assessments $(62.35[ \pm 8.49]$ vs. $84.70[ \pm$ 


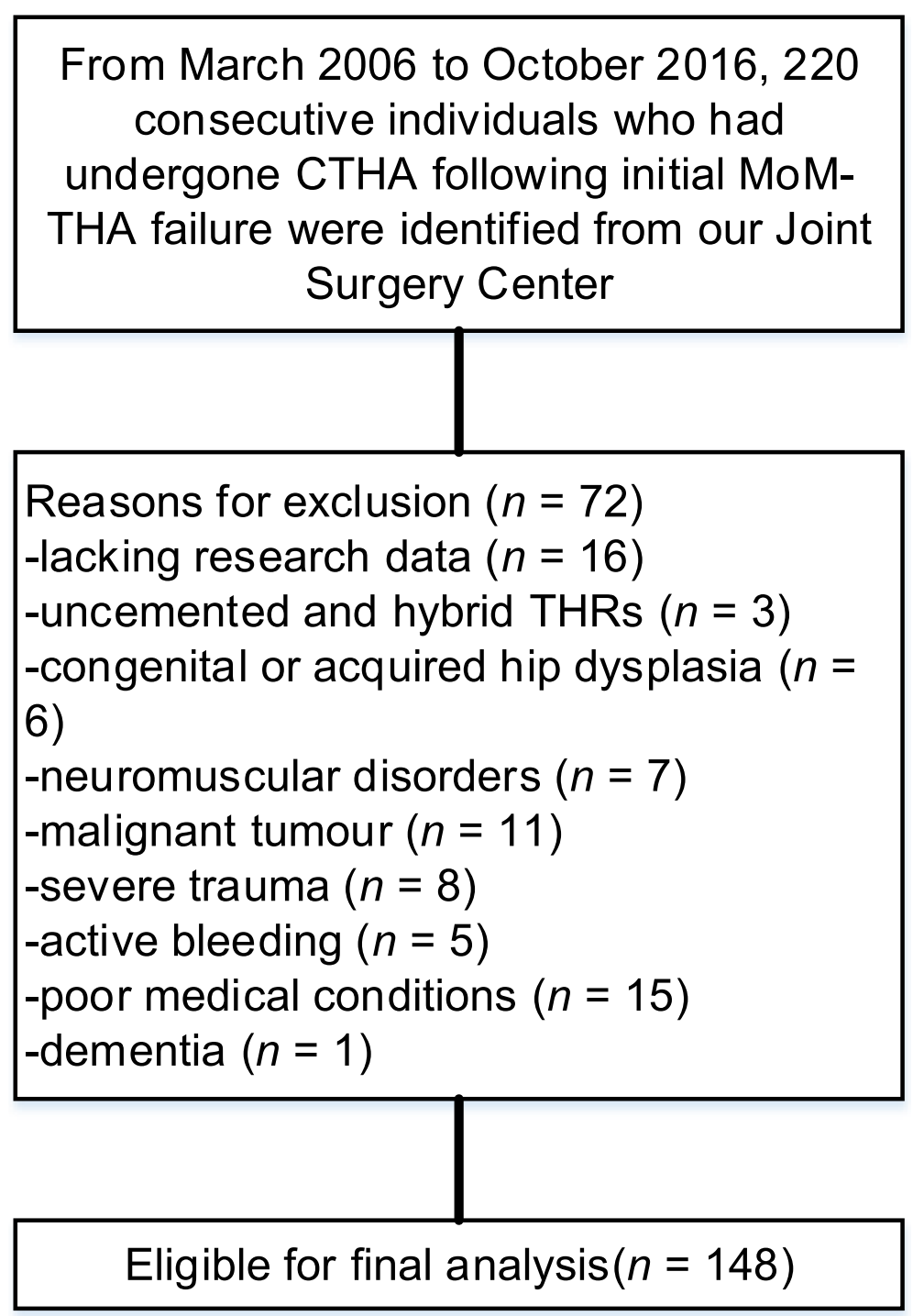

Fig. 1 Flow diagram presenting the method for identification of individuals to evaluate the clinical and radiological outcomes of patients who had experienced a primary metal-on-metal total hip replacement (MoM-THR) revised to cemented THR (CTHR)

14.68], respectively, $p<0.001)$, between 2 years after revision and 4 years after revision $(88.76[ \pm 9.27]$ vs. $91.40[ \pm$ 10.59 ], respectively, $p<0.001)$, between 4 years after revision and 6 years after revision $(91.40[ \pm 10.59]$ vs. $88.16[ \pm$ 10.02], respectively, $p<0.001$ ), and between 6 years after revision and 8 years after revision $(88.16[ \pm 10.02]$ vs. $87.35 \pm 11.28$, respectively, $p<0.001)$. The HHS peaked at 4 years after conversion $(91.40[ \pm 10.59])$. There was no significant drop off at the final follow-up starting with the fourth year after conversion.

\section{Radiological outcomes}

At the last review, 27 key orthopaedic complications in 148 cases were observed (Table 3). The rate of key orthopaedic complication was $18.2 \%$. Seven (4.7\%) cases experienced a CTHR failure at a mean of 4.4 years (3-6 years) after revision MoM-THR, mostly attributed to recurrent dislocation. Eight (5.4\%) had a loosening at a mean of $2.6( \pm 1.1)$ years after conversion. Ten $(6.8 \%)$ had a dislocation. Heterotopic ossification ( $\geq$ grade 3 ) failed to be detected throughout the follow-up period. Two (1.4\%) had a periprosthesis fracture.

\section{Discussion}

The current study shows that the conversion from primary MoM-THR to CTHR tends to have favourable clinical outcomes, involving an acceptable functional score and a low rate of the key orthopaedic complications. The acetabular component tends to have loss of acetabular bone stock after removal of MoM articulation 
Table 1 Baseline data on the overall population of 148 patients

\begin{tabular}{ll}
\hline Variable & CTHR $(\boldsymbol{n}=\mathbf{1 4 8})$ \\
\hline Sex, M/F & $80 / 68$ \\
Age $(y)$ & $52.4(46-62)$ \\
BMI $\left(\mathrm{kg} / \mathrm{m}^{2}\right)$ & $26.7(20-31)$ \\
BMD & $-3.58(-3.1$ to -3.9$)$ \\
Side, left/right & $83 / 65$ \\
Time to conversion (y) & $6.8(2-9)$ \\
Comorbidities, n\% & \\
Hypertension & $49(33.1)$ \\
Diabetes mellitus & $31(20.9)$ \\
Hypertension and Diabetes mellitus & $12(8.1)$ \\
Mechanism of injury, n\% & \\
Traffic & $34(22.9)$ \\
Falling & $69(46.6)$ \\
Tamp & $35(23.6)$ \\
Other & $10(6.8)$ \\
ASA scale, n\% & \\
I & $43(29.1)$ \\
II & $75(50.7)$ \\
III & $30(20.3)$ \\
FHS prior to revision & $62.35 \pm 8.49$ \\
\hline
\end{tabular}

$C T H R$ cemented total hip replacement, $B M I$ body mass index, $B M D$ bone mineral density, MOM-THR metal-on-metal total hip replacement, ASA American Society of Anesthesiologists, HHS Harris hip scores

[17]. As well, removal of the MoM articulation was associated with reducing metal ion levels [18]. The utilisation of a cemented bearing for revision MoM-THR theoretically contributes to decreasing the high associated dislocation rate [19]. Maybe, CTHR is a preferred option for management of patients with MoM-THR failure,

Table 2 Clinical outcomes of patients undergoing a primary MoM-THR revised to CTHR

\begin{tabular}{ll}
\hline HHS, month(s) after conversion & CTHR $(\boldsymbol{n}=\mathbf{1 4 8})$ \\
\hline 3 & $80.01 \pm 9.75^{\mathrm{a}}$ \\
6 & $86.14 \pm 6.31$ \\
12 & $88.52 \pm 6.83$ \\
24 & $88.76 \pm 9.27^{\mathrm{a}}$ \\
48 & $91.40 \pm 10.59^{\mathrm{a}}$ \\
72 & $88.16 \pm 10.02^{\mathrm{a}}$ \\
96 & $87.35 \pm 11.28^{\mathrm{a}}$ \\
120 & $85.72 \pm 13.65$ \\
Final follow-up & $84.70 \pm 14.68^{\mathrm{a}}$ \\
\hline
\end{tabular}

${ }^{a}$ Statistically significant values. CTHR cemented total hip replacement, MoMTHR metal-on-metal total hip replacement, HHS Harris hip scores although the impact of residual metal ions on CTHR and the extent of the impact are still unclear [20,21].

Although use of large-diameter MoM articulations, potential drawbacks associated with MoM cups have been frequently reported in published literatures [3, 8, 22]. These drawbacks primarily involve ARMD, periarticular pseudotumor, and systemic complications related to metal ions, which restricts the further promotion of MoM-THR $[8,20]$. MoM-THR with wear characteristics (i.e., fretting corrosion) releasing metal ions, stimulating the surrounding bone and tendon tissue, leading to osteoporosis and tendon tissue hyperplasia, which in turn triggers the instability after MoM-THR surgery has been regarded as a leading initiator for subsequent revision [23, 24]. When MoM-THR was revised to CTHR, such a dilemma related to wear characteristics (i.e., fretting corrosion) still exists [25]. Furthermore, disassociation of the femoral head from the stem following gross wear of the taper is common in patients who were treated with MoM-THR [7].

Previous reports $[23,24]$ have shown that the increased migration of CTHR revision following prior MoM-THR failure, which was associated with dislocation, especially if recurrent. Cemented components can improve osteoporosis to a certain extent [26]. However, it is unclear whether the damage triggered by the residual metal ions to bone continues after conversion, or whether there was a positive correlation between the CTHR stability and decreasing serum cobalt and chromium levels $[18,25]$, although several studies [27, 28] have shown that after the conversion of MoM-THR to CTHR, serum cobalt and chromium levels were reduced.

Decreased metal ion level, coupled with the potential to resist impingement results in improved symptoms initiated by ARMD in patients who experienced this conversion [28]. Lainiala et al. [29] reported approximately 2500 individuals who experienced a primary MoM-THR and revealed that $63 \%$ revision surgery was attributed to ARMD. Jennings et al. [3] performed a retrospective study involving $54 \mathrm{MoM}$-THR surgeries and showed that cup wear triggered by ARMD was the leading cause for revision MoM-THR. Crawford et al. [10] performed a large consecutive series of 188 individuals (203 hips) who were revised for MoM-THR failure and revealed that re-revision which was mostly attributed to aseptic loosening and dislocation was required in 16 hips (7.9\%), even though the metal ion levels significantly declined. Moreover, they pointed out that there were noteworthy complications specifically in patients with pseudotumor related to ARMD. Borton et al. [9] reported the outcomes of 180 revisions for failed MoM-THR and showed that cobalt-chromium-containing bearing surfaces are associated with poor functional outcomes.

MoM-THR revised to THR for ARMD had various complications and poor clinical outcomes [23, 24]. 


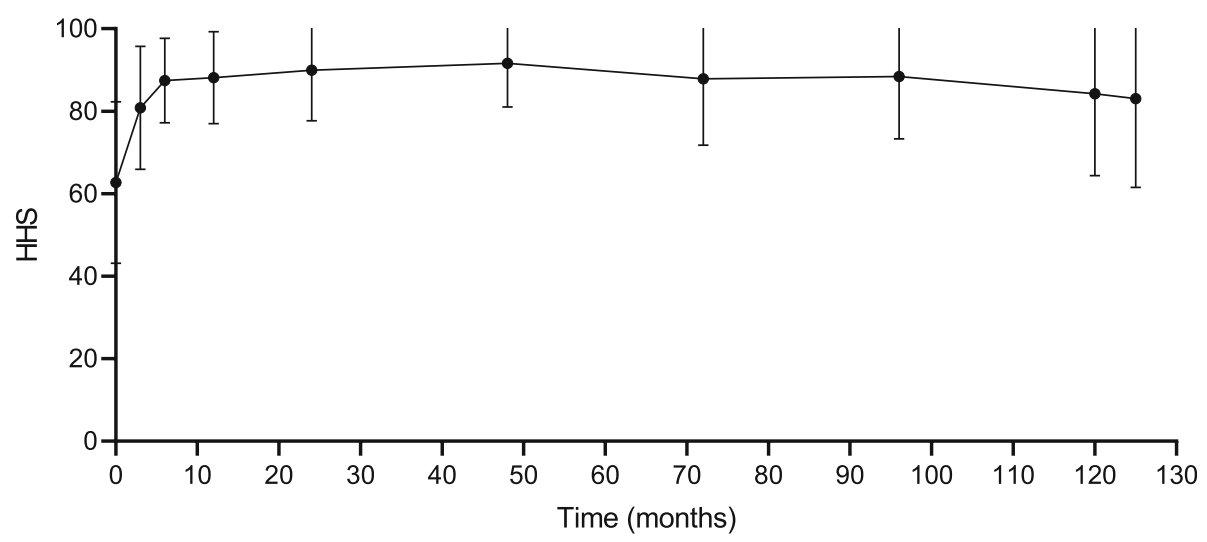

Fig. 2 The variation trend of postoperative functional scores

However, the timing of MoM-THR revised to THR and the component type of THR have a growing controversy [30]. In the previous reports [31, 32], CTHR is commonly used to revise MoM-THR. Presently, the use of cement-based prosthetics to resist poor bone condition seems to be a trend [32]. Studies [33, 34] assessing early revision of MoM-THR showed superior results before the pseudotumor appeared. Nevertheless, little is known about these results following pseudotumor revision [35].

Several limitations should be acknowledged. First, this is a retrospective analysis with inherent drawbacks. Second, the analysis of variables may be limited by sample size and lack of a control group. Nonetheless, in view of the 10-year follow-up data described following MoMTHR revised to CTHR, we deem that the conclusions drawn from this study are important. Third, our baseline data does not involve the end-organ damage related to ARMD, although there has become an area of growing concern, with the literature [36, 37] describing associated the end-organ damage (i.e., cardiotoxicity), corrosion, and fretting in individuals undergoing CTHR revision. Fourth, we did not measure the blood metal ion levels during patient follow-up, and did not involve the blood metal ion thresholds to predict ARMD,

Table 3 Radiological outcomes of patients undergoing a primary MoM-THR revised to CTHR

\begin{tabular}{ll}
\hline Variable, $\mathbf{n} \%$ & CTHR $(\boldsymbol{n}=\mathbf{1 4 8})$ \\
\hline Implant failure & $7(4.7)$ \\
Loosening & $8(5.4)$ \\
Dislocation & $10(6.8)$ \\
Heterotopic ossification ( $\geq$ grade 3$)$ & $0(0.0)$ \\
Periprosthesis fracture & $2(1.4)$
\end{tabular}

CTHR cemented total hip replacement, MoM-THR metal-on-metal total hip replacement although these thresholds tend to be effective for identifying individuals at low risk of ARMD.

\section{Conclusions}

This study demonstrated CTHR might yield encouraging functional scores and a tolerable rate of key orthopaedic complication. While not presently appreciated in previous reports [8, 17], supplementary evidence will be needed to explicit if ARMD-related wear and loosening are slowed down in the long term with CTHR constructs. In addition, patients with failed MoM-THR revised to CTHR should ponder ARMD-related complications and subsequently the possibility of the need for revision surgery, or balance the potential benefits of improving quality of life against the ARMD-related risks.

\section{Acknowledgements \\ Not applicable.}

\section{Authors' contributions}

WY, MC, and XSZ performed the data collection and analysis and participated in manuscript writing. $X C Z, M Z, J Y, J Z$, and $G H$ participated in the study design and performed the operations and the database setup and statistical analysis. All authors have read and approved the final manuscript.

\section{Funding}

Funding for this study was received from the National Natural Science Foundation of China (Grant No. 81971315). This study failed to receive any grant from funding agencies in the public, commercial, or not-for-profit sectors.

Availability of data and materials

The datasets used and/or analysed during the current study are available from the corresponding author on reasonable request.

\section{Ethics approval and consent to participate}

This study was approved by the Investigational Ethics Review Board (The First Affiliated Hospital, Sun Yat-sen University), and an exemption from informed consent was obtained from the board.

Consent for publication

Not applicable.

Competing interests

The authors declare no competing interests. 


\section{Author details}

'Department of Orthopaedics, The First Affiliated Hospital, Sun Yat-sen University, No. 58, Zhongshan 2nd Road, Yuexiu District, Guangzhou 510080, China. ${ }^{2}$ Department of Pediatrics, The First Affiliated Hospital, Sun Yat-sen University, No. 58, Zhongshan 2nd Road, Yuexiu District, Guangzhou 510080, China. ${ }^{3}$ Department of Orthopaedics, Jinshan Hospital, Fudan University, Longhang Road No. 1508, Jinshan District, Shanghai 201508, China. ${ }^{4}$ Department of Orthopaedics, The Affiliated Hospital of Jiangnan University, No. 1000, Hefeng Road, Binhu District, Wuxi 21400, Jiangsu, China. ${ }^{5}$ Department of Orthopaedics, The Third People's Hospital of Wuxi, No. 1000, Hefeng Road, Binhu District, Wuxi 214000, Jiangsu, China. ${ }^{6}$ Department of Urinary surgery, The First Affiliated Hospital, Sun Yat-sen University, No. 58, Zhongshan 2nd Road, Yuexiu District, Guangzhou 510080, China.

\section{Received: 25 March 2020 Accepted: 17 November 2020} Published online: 21 November 2020

\section{References}

1. Matharu GS, Pandit HG, Murray DW. Poor survivorship and frequent complications at a median of 10 years after metal-on-metal hip resurfacing revision. Clin Orthop Relat Res. 2017;475(2):304-14. https://doi.org/10.1007/ s11999-016-4882-4.

2. Mohaddes M, Naucler E, Karrholm J, Malchau H, Odin D, Rolfson O. Implant survival and patient-reported outcome following total hip arthroplasty in patients 30 years or younger: a matched cohort study of 1,008 patients in the Swedish hip Arthroplasty register. Acta Orthop. 2019;90(3):249-52. https://doi.org/10.1080/17453674.2019.1599776.

3. Jennings JM, White S, Martin JR, Yang CC, Miner TM, Dennis DA. Revisions of modular metal-on-metal THA have a high risk of early complications. Clin Orthop Relat Res. 2019;477(2):344-50. https://doi.org/10.1097/corr. 0000000000000363.

4. Matharu GS, Berryman F, Dunlop DJ, Revell MP, Judge A, Murray DW, Pandit HG. No threshold exists for recommending revision surgery in metal-onmetal hip Arthroplasty patients with adverse reactions to metal debris: a retrospective cohort study of 346 revisions. J Arthroplast. 2019;34(7):148391. https://doi.org/10.1016/j.arth.2019.03.022.

5. Lehtovirta L, Reito A, Lainiala O, Parkkinen J, Hothi H, Henckel J, Hart A, Eskelinen A. Host-specific factors affect the pathogenesis of adverse reaction to metal debris. BMC Musculoskelet Disord. 2019;20. https://doi.org/10.1186/ s12891-019-2578-0.

6. Wegrzyn J, Pibarot V, Jacquel A, Carret JP, Bejui-Hugues J, Guyen O Acetabular reconstruction using a Kerboull cross-plate, structural allograft and cemented dual-mobility cup in revision THA at a minimum 5-year follow-up. J Arthroplast. 2014;29(2):432-7. https://doi.org/10.1016/j.arth.2013. 05.030 .

7. Bonner B, Arauz P, Klemt C, Kwon YM. Outcome of re-revision surgery for adverse local tissue reaction in metal-on-polyethylene and metal-on-metal Total hip Arthroplasty. J Arthroplast. 2020;35(6):S284-S8. https://doi.org/10. 1016/j.arth.2020.02.006

8. Meyer H, Mueller T, Goldau G, Chamaon K, Ruetschi M, Lohmann CH. Corrosion at the cone/taper Interface leads to failure of large-diameter metal-on-metal Total hip Arthroplasties. Clin Orthop Relat Res. 2012;470(11): 3101-8. https://doi.org/10.1007/s11999-012-2502-5.

9. Borton ZM, Mumith AS, Nicholls AJ, Pearce AR, Briant-Evans TW, Griffiths JT. The outcome of revision surgery for failed metal-on-metal Total hip Arthroplasty. J Arthroplast. 2019;34(8):1749-54. https://doi.org/10.1016/j.arth. 2019.03.067.

10. Crawford DA, Adams JB, Morris MJ, Berend KR, Lombardi AV. Revision of failed metal-on-metal Total hip Arthroplasty: midterm outcomes of 203 consecutive cases. J Arthroplast. 2019;34(8):1755-60. https://doi.org/10.1016/ j.arth.2019.04.019.

11. Liu TJ, Hua XX, Yu WG, Lin JL, Zhao MD, Liu J, Zeng XS. Long-term followup outcomes for patients undergoing primary total hip arthroplasty with uncemented versus cemented femoral components: a retrospective observational study with a 5-year minimum follow-up. J Orthop Surg Res. 2019;14(1). https://doi.org/10.1186/s13018-019-1415-3.

12. Amstutz HC, Le Duff MJ, Campbell PA, Dorey FJ. The effects of technique changes on aseptic loosening of the femoral component in hip resurfacing. Results of 600 conserve plus with a 3 to 9 year follow-up. J Arthroplast. 2007;22(4):481-9. https://doi.org/10.1016/j.arth.2006.08.001.
13. Rokkum M, Brandt M, Bye K, Hetland KR, Waage S, Reigstad A. Polyethylene wear, osteolysis and acetabular loosening with an HA-coated hip prosthesis - a follow-up of 94 consecutive arthroplasties. J Bone Joint Surg Br. 1999; 81B(4):582-9. https://doi.org/10.1302/0301-620x.81b4.8715.

14. Smith AJ, Dieppe P, Vernon K, Porter M, Blom AW. Natl joint registry England W. failure rates of stemmed metal-on-metal hip replacements: analysis of data from the National Joint Registry of England and Wales. Lancet. 2012;379(9822):1199-204. https://doi.org/10.1016/s01406736(12)60353-5.

15. Burd TA, Lowry KJ, Anglen JO. Indomethacin compared with localized irradiation for the prevention of heterotopic ossification following surgical treatment of acetabular fractures. J Bone Joint Surg Am. 2001;83A(12):17838. https://doi.org/10.2106/00004623-200112000-00003.

16. Unger AS, Lewis RJ, Gruen T. Evaluation of a porous tantalum uncemented acetabular cup in revision total hip arthroplasty - clinical and radiological results of 60 hips. J Arthroplast. 2005;20(8):1002-9. https://doi.org/10.1016/j. arth.2005.01.023.

17. Korovessis P, Petsinis G, Repanti M, Repantis T. Metallosis after contemporary metal-on-metal total hip arthroplasty - five to nine-year follow-up. J Bone Joint Surg Am. 2006;88A(6):1183-91. https://doi.org/10.2106/jbjs.D.02916.

18. Waldstein W, Koller U, Springer B, Kolbitsch P, Brodner W, Windhager R, Lass R. Serum cobalt concentrations remain at low levels at a minimum of 20 years following metal-on-metal total hip arthroplasty. Bone Joint Res. 2020;9(3):146-51. https://doi.org/10.1302/2046-3758.93. Bjr-2019-0218.R1.

19. Smith AJ, Dieppe P, Howard PW, Blom AW. Natl joint registry England W. failure rates of metal-on-metal hip resurfacings: analysis of data from the National Joint Registry for England and Wales. Lancet. 2012;380(9855):175966. https://doi.org/10.1016/s0140-6736(12)60989-1.

20. Levine BR, Hsu AR, Skipor AK, Hallab NJ, Paprosky WG, Galante JO, Jacobs JJ. Ten-year outcome of serum metal ion levels after primary Total hip Arthroplasty a concise follow-up of a previous report. J Bone Joint Surg Am. 2013;95A(6):512-8. https://doi.org/10.2106/jbjs.L.00471.

21. Ko LJM, Pollag KE, Yoo JY, Sharkey PF. Serum metal ion levels following Total hip Arthroplasty with modular dual mobility components. J Arthroplast. 2016;31(1):186-9. https://doi.org/10.1016/j.arth.2015.07.035.

22. Bouveau V, Haen TX, Poupon J, Nich C. Outcomes after revision of metal on metal hip resurfacing to total arthroplasty using the direct anterior approach. Int Orthop. 2018;42(11):2543-8. https://doi.org/10.1007/s00264018-3858-2.

23. Law JI, Crawford DA, Adams JB, Lombardi AV. Metal-on-metal Total hip revisions: pearls and pitfalls. J Arthroplast. 2020;35(6):S68-72. https://doi.org/ 10.1016/j.arth.2020.01.011.

24. Lainiala O, Reito A, Nieminen J, Eskelinen A. Complications and re-revisions after revisions of 528 metal-on-metal hips because of adverse reaction to metal debris. Acta Orthop. 2020;91(4):365-71. https://doi.org/10.1080/ 17453674.2020.1748351.

25. Higgs GB, Hanzlik JA, MacDonald DW, Gilbert JL, Rimnac CM, Kurtz SM. Implant res $\mathrm{Ctr}$ writing $\mathrm{C}$. is increased modularity associated with increased fretting and corrosion damage in metal-on-metal Total hip Arthroplasty devices? A retrieval study. J Arthroplast. 2013;28(8):2-6. https://doi.org/10. 1016/j.arth.2013.05.040.

26. Chougle A, Hemmady MV, Hodgkinson JP. Severity of hip dysplasia and loosening of the socket in cemented total hip replacement - a long-term follow-up. J Bone Joint Surg Br. 2005;87B(1):16-20.

27. Carlson BC, Bryan AJ, Carrillo-Villamizar NT, Sierra RJ. The utility of metal ion trends in predicting revision in metal-on-metal Total hip Arthroplasty. J Arthroplast. 2017;32(9):S214-S9. https://doi.org/10.1016/j.arth.2017.02.031.

28. Civinini R, Lepri AC, Carulli C, Matassi F, Villano M, Innocenti M. Patients following revision Total hip Arthroplasty with modular dual mobility components and cobalt-chromium inner metal head are at risk of increased serum metal ion levels. J Arthroplast. 2020;35(6):S294-S8. https://doi.org/10. 1016/j.arth.2020.02.050.

29. Lainiala OS, Reito AP, Nieminen JJ, Eskelinen AP. Declining Revision Burden of Metal-on-Metal Hip Arthroplasties. J Arthroplasty. 2019;34(9):2058. https:// doi.org/10.1016/j.arth.2019.04.058.

30. Wu A, Weaver MJ, Heng MM, Urman RD. Predictive model of surgical time for revision Total hip Arthroplasty. J Arthroplast. 2017;32(7):2214-8. https:// doi.org/10.1016/j.arth.2017.01.056

31. Hothi HS, Berber R, Panagiotopoulos AC, Whittaker RK, Rhead C, Skinner JA, Hart AJ. Clinical significance of corrosion of cemented femoral stems in 
metal-on-metal hips: a retrieval study. Int Orthop. 2016;40(11):2247-54 https://doi.org/10.1007/s00264-016-3116-4.

32. Chen Z, Chen WL, Yu WG, Zhao MD, Lin JL, Zhou CM, Chen H, Ye JX, Zeng XS, Zhuang JT. Mid-term outcomes of uncemented or cemented arthroplasty revision following metal-on-metal total hip arthroplasty failure: a retrospective observational study. J Int Med Res. 2020;48(6). https://doi. org/10.1177/0300060520932051.

33. Hasegawa M, Naito Y, Yamaguchi T, Miyazaki S, Wakabayashi H, Sudo A. Factors associated with symptomatic pseudotumors following metal-onmetal total hip arthroplasty. BMC Musculoskelet Disord. 2016;17:1-5. https:// doi.org/10.1186/s12891-016-1317-z.

34. Hjorth MH, Stilling M, Soballe K, Bolvig LH, Thyssen JP, Mechlenburg I, Jakobsen SS. No association between pseudotumors, high serum metal-ion levels and metal hypersensitivity in large-head metal-on-metal total hip arthroplasty at 5-7-year follow-up. Skelet Radiol. 2016;45(1):115-25. https:// doi.org/10.1007/s00256-015-2264-8.

35. Liow MHL, Dimitriou D, Tsai TY, Kwon YM. Preoperative risk factors associated with poor outcomes of revision surgery for "Pseudotumor" in patients with metal-on-metal hip Arthroplasty. J Arthroplast. 2016;31(12): 2835-42. https://doi.org/10.1016/j.arth.2016.05.034.

36. Martin AJ, Jenkins DR, van Citters DW. Role of corrosion in taper failure and head disassociation in total hip arthroplasty of a single design. J Orthop Res. 2018;36(11):2996-3003. https://doi.org/10.1002/jor.24107.

37. Steinberg J, Shah KM, Gartland A, Zeggini E, Wilkinson JM. Effects of chronic cobalt and chromium exposure after metal-on-metal hip resurfacing: an Epigenome-wide association pilot study. J Orthop Res. 2017;35(10):2323-8 https://doi.org/10.1002/jor.23525.

\section{Publisher's Note}

Springer Nature remains neutral with regard to jurisdictional claims in published maps and institutional affiliations.

Ready to submit your research? Choose BMC and benefit from:

- fast, convenient online submission

- thorough peer review by experienced researchers in your field

- rapid publication on acceptance

- support for research data, including large and complex data types

- gold Open Access which fosters wider collaboration and increased citations

- maximum visibility for your research: over $100 \mathrm{M}$ website views per year

At BMC, research is always in progress.

Learn more biomedcentral.com/submissions 